\title{
Solid-Phase Extraction Followed by HPLC for the Determination of Phosphorus(V) and Arsenic(V)
}

\author{
Hiroaki MATSUMIYA, ${ }^{\dagger}$ Takaaki KIKAI, and Masataka HiRAIDE \\ Department of Molecular Design and Engineering, Graduate School of Engineering, Nagoya University, \\ Furo-cho, Chikusa, Nagoya 464-8603, Japan
}

\begin{abstract}
Traces of $\mathrm{P}(\mathrm{V})$ and $\mathrm{As}(\mathrm{V})$ in sample solutions were converted into heteropoly molybdic acids at $\mathrm{pH} 1.5$ and collected onto polyoxyethylene(20)-4-isononylphenoxy ether-coated Amberlite XAD-4 particles. The desorption was carried out with 0.3 M tetramethylammonium hydroxide solution for the HPLC analysis. Molybdophosphoric and molybdoarsenic acids were separated from excess molybdate by ion-pair reversed phase HPLC, though the peaks of $\mathrm{P}(\mathrm{V})$ and As $(\mathrm{V})$ could not be resolved. However, the selective decomposition of molybdoarsenic acid with citric acid allowed the differential determination of $\mathrm{P}(\mathrm{V})$ and $\mathrm{As}(\mathrm{V})$ at the $\mathrm{ng} \mathrm{mL}^{-1}$ level. The proposed method was applied to the analysis of high-purity iron for $\mathrm{P}$ and As.
\end{abstract}

(Received August 21, 2008; Accepted October 1, 2008; Published February 10, 2009)

\section{Introduction}

Solid-phase extraction (SPE) is a useful separation technique in trace analysis. ${ }^{1-4} \quad$ SPE has been developed to replace conventional solvent extraction, in which toxic, volatile, and flammable solvents are frequently used. Not only decreased solvent usage but also simpler operation is the main advantage of SPE. A wide variety of functionalized sorbents have been prepared for the intended uses. However, the preparation of such sorbents sometimes requires tedious multistep syntheses.

As an attractive alternative sorbent, we have studied the use of admicelles, which are surfactant aggregates formed on liquidsolid interfaces. ${ }^{5-8}$ Typically, simple mixing of an ionic surfactant with an oppositely charged mineral oxide in water affords admicelles, which provide nanometer-sized hydrophobic extraction media similar to those of normal micelles. Depending on the surfactant concentration and the ionic strength, the surfactant molecules self-assemble at the interface into various forms of aggregates, such as monolayered, bilayered, spherical, spheroidal, and cylindrical structures. ${ }^{9}$ Sparingly water-soluble compounds can be incorporated into the hydrocarbon cores of these adsorbed aggregates. Because the surfactant aggregates are supported on a solid material, the handling of admicelles is free from difficulties encountered in separating normal micelles from the bulk aqueous phase.

Another type of admicelles can also be prepared using the hydrophobic interaction between nonionic surfactants and hydrophobic solid supports. ${ }^{10-12}$ For example, the combination of polyoxyethylene(20)-4-isononylphenoxy ether (PONPE) and an Amberlite XAD-4 resin provided a unique sorbent for SPE, where the ethylene oxide chains of the surfactant interacted with $\mathrm{Fe}(\mathrm{III})$ in $6-8 \mathrm{M} \mathrm{HCl}$ similarly to diethyl ether in solvent extraction. ${ }^{12}$ The selective sorption of $\mathrm{Fe}(\mathrm{III})$ allowed the

$\dagger$ To whom correspondence should be addressed.

E-mail: h-matsu@numse.nagoya-u.ac.jp matrix-removal for the multielement analysis of iron metals by ICP-MS. However, the determination of $\mathrm{P}$ and As was not attempted because of the low sensitivity of ICP-MS for these elements. The chemical and physical properties of iron metals are strongly affected by $\mathrm{P}$ and As; hence, their determination is important.

The Japanese Industrial Standards Committee recommends the determination of $\mathrm{P}$ and As in iron metals by solvent extraction followed by spectrophotometry with molybdate. ${ }^{13,14}$ Coprecipitation with beryllium hydroxide followed by hydride generation $(\mathrm{HG})$ can also be combined with the spectrophotometric determination of As with diethyldithiocarbamate. ${ }^{14}$ Although the determination is possible at low $\mu \mathrm{g} \mathrm{g}^{-1}$ levels, more sensitive methods are desired. On the other hand, the combination of HG with microwave induced plasma- ${ }^{15}$ or ICP-AES ${ }^{16,17}$ allowed the determination of As at the $1 \mu \mathrm{g} \mathrm{g}^{-1}$ level. $\mathrm{HG}$ was also combined with $\mathrm{GC}$ for the simultaneous determination of $\mathrm{P}$ and As at low $\mu \mathrm{g} \mathrm{g}^{-1}$ levels. ${ }^{18}$ Aimoto et al. reported a unique $\mathrm{HG}$ method, in which gaseous $\mathrm{PH}_{3}$ was generated by electrolysis of an iron sample with heating for the determination of $\mathrm{P}$ at low $\mu \mathrm{g}^{-1}$ levels by ICP-AES. ${ }^{19}$ These HG methods, however, require special instruments. In contrast to the frequent use of HG, SPE was seldom used for the determination of $\mathrm{P}$ and As in iron metals. Recently, Yamane and Tsuchiya have reported a unique SPE method, in which molybdovanadophosphoric acid was collected onto a Sephadex G-25 gel and the catalytic oxidation of thiamine by the retained acid was used for the indirect fluorometric determination of $\mathrm{P}$ at the $\mathrm{ng} \mathrm{\textrm {g } ^ { - 1 }}$ level. ${ }^{20}$ Although highly sensitive, this method does not seem to be applicable to As because of the high specificity for P.

In the present study, we found that heteropoly molybdic acids of $\mathrm{P}$ and As were sorbed onto the PONPE-admicelles at around $\mathrm{pH} 1.5$, where $\mathrm{Fe}(\mathrm{III})$ was negligibly sorbed. Therefore, the selective SPE was combined with HPLC and applied to the analysis of high-purity iron metal. Because the SPE provided almost complete removal (>99.98\%) of the Fe(III) matrix, the subsequent HPLC was free from any matrix-interferences such 
as overloading and fouling of the HPLC column. Although the mutual separation of $\mathrm{P}$ and As was not achieved, this problem was successfully overcome by the selective decomposition of molybdoarsenic acid with citric acid, which allowed the differential determination of $\mathrm{P}$ and As at the fractional $\mu \mathrm{g} \mathrm{g}^{-1}$ level.

\section{Experimental}

\section{Apparatus and reagents}

An HPLC system consisted of a Jasco PU-2080 pump, a Rheodyne $7125 \mathrm{i}$ six-way injection valve with a $100-\mu \mathrm{L}$ sample loop, a Merck Chromolith Performance RP-18e column (4.6 mm i.d. $\times 100 \mathrm{~mm}$, packed with monolithic porous $n$-octadecylsilanized silica), and a Jasco UV-2070 spectrophotometric detector.

A PONPE solution $\left(11 \mathrm{mg} \mathrm{mL}^{-1}\right)$ was prepared by dissolving polyoxyethylene(20)-4-isononylphenoxy ether (Tokyo Kasei) in water. Amberlite XAD-4 (macroreticular styrene-divinylbenzene copolymer, Rohm and Haas) was pulverized to $100-200 \mu \mathrm{m}$ and washed with $99.5 \%(\mathrm{w} / \mathrm{w})$ ethanol, followed by water.

A standard $\mathrm{P}(\mathrm{V})$ solution $(1.0 \mathrm{mg} \mathrm{mL}-1)$ was prepared by dissolving potassium dihydrogenphosphate in water. A standard $\mathrm{As}(\mathrm{V})$ solution $\left(1.0 \mathrm{mg} \mathrm{mL}-1, \mathrm{H}_{3} \mathrm{AsO}_{4}\right.$ in $0.5 \mathrm{M} \mathrm{HNO}_{3}$, CertiPUR) was purchased from Merck. A molybdate solution (8.0 mg mL $\mathrm{mL}^{-1}$ as Mo) was prepared by dissolving sodium molybdate dihydrate (Nacalai Tesque) in water. An EDTA solution $(0.22 \mathrm{M})$ was prepared by dissolving disodium ethylenediaminetetraacetate dihydrate (Dojindo) in water. A citric acid solution $(50 \mathrm{mg} \mathrm{mL}-1$ ) was prepared by dissolving citric acid in water. Hydrochloric acid (12 M) and nitric acid $(16 \mathrm{M})$ were of ultra-pure grade (Kanto Kagaku). An aqueous $25 \%(\mathrm{w} / \mathrm{w})$ tetramethylammonium hydroxide (TMAH) solution (ultra-pure grade) was purchased from Tama Kagaku Kogyo. An aqueous $65 \%(\mathrm{w} / \mathrm{w})$ acetonitrile solution containing $0.65 \%$ $(\mathrm{w} / \mathrm{w})$ tetra- $n$-butylammonium bromide $(\mathrm{TBABr})$ and $0.10 \%$ $(\mathrm{w} / \mathrm{w})$ trifluoroacetic acid (TFA) was used as a mobile phase at a flow rate of $2.0 \mathrm{~mL} \mathrm{~min}^{-1}$

An $\mathrm{Fe}(\mathrm{III})$ solution (20 $\left.\mathrm{mg} \mathrm{mL}^{-1}\right)$ was prepared by decomposing $500 \mathrm{mg}$ of iron metal $(99.998 \%$ purity, powder, Johnson Matthey) with $1.5 \mathrm{~mL}$ each of $12 \mathrm{M} \mathrm{HCl}$ and $16 \mathrm{M}$ $\mathrm{HNO}_{3}$ at $\mathrm{ca} .60^{\circ} \mathrm{C}$ and diluting the solution to $25 \mathrm{~mL}$ with water. Certified reference materials for high-purity iron, NIST 2168 (chips) and CMSI 1010b (powder), were obtained from the National Institute of Standard and Technology and the China Metallurgical Standardization Research Institute, respectively.

All reagents used were of reagent grade (Wako Jun-yaku), unless otherwise stated. Water was purified with a Millipore Milli-Q Gradient A-10 system.

\section{Preparation of SPE sorbent}

A 100-mg amount of XAD-4 was gently mixed with $3.0 \mathrm{~mL}$ of PONPE solution for $2 \mathrm{~h}$ and then washed with $5 \mathrm{~mL}$ of $0.3 \mathrm{M}$ TMAH solution. The resulting PONPE-admicelles were packed into a column ( $5 \mathrm{~mm}$ i.d. $\times 8 \mathrm{~mm})$, rinsed with $5 \mathrm{~mL}$ of water, and conditioned with $15 \mathrm{~mL}$ of $0.03 \mathrm{M} \mathrm{HCl}$.

\section{Analytical procedure}

A 100- or 500-mg iron sample was decomposed with $1.5 \mathrm{~mL}$ each of $12 \mathrm{M} \mathrm{HCl}$ and $16 \mathrm{M} \mathrm{HNO}_{3}$ at $c a .60^{\circ} \mathrm{C}$. After cooling to room temperature, the solution was diluted to $25 \mathrm{~mL}$ with water.

An aliquot of the sample solution containing 5-40 mg of Fe was mixed with an equimolar EDTA solution (e.g., $3.25 \mathrm{~mL}$ for $40 \mathrm{mg} \mathrm{Fe}$ ) while adjusting the $\mathrm{pH}$ to 1.5 with $25 \%$ (w/w) TMAH solution. The solution was diluted to $10 \mathrm{~mL}$ with water, mixed with $0.30 \mathrm{~mL}$ of molybdate solution, and left to stand for $5-10$

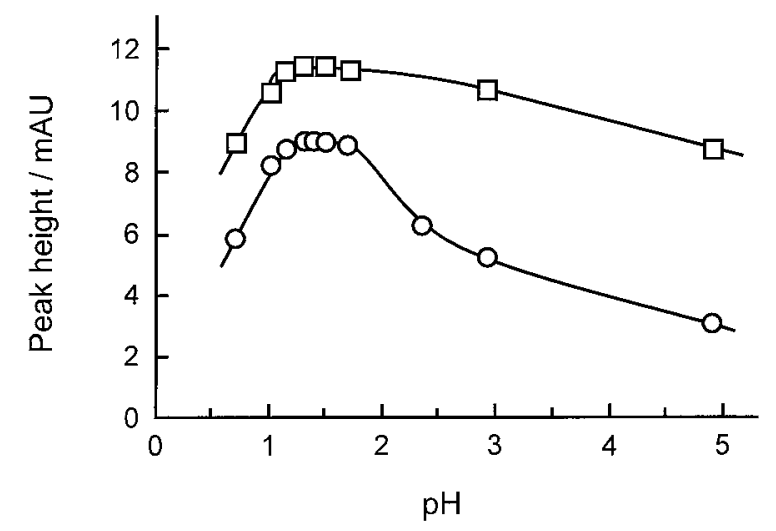

Fig. 1 Formation of heteropoly molybdic acids of P (O) and As ( $\square$ ) at different $\mathrm{pH}$ 's. Concentrations: $\mathrm{P}(\mathrm{V}), 60 \mathrm{ng} \mathrm{mL}^{-1}$; $\mathrm{As}(\mathrm{V}), 120 \mathrm{ng}$ $\mathrm{mL}^{-1}$; $\mathrm{Mo}(\mathrm{VI}), 0.24 \mathrm{mg} \mathrm{mL}^{-1}$.

min to form heteropoly molybdic acids. The resulting solution was passed through an SPE column at a flow rate of $1.0 \mathrm{~mL}$ $\mathrm{min}^{-1}$. After washing the column with $5.0 \mathrm{~mL}$ of $0.03 \mathrm{M} \mathrm{HCl}$, the retained $\mathrm{P}$ and As were desorbed with $1.0 \mathrm{~mL}$ of $0.3 \mathrm{M}$ TMAH solution. The desorption was repeated once more with $1.0 \mathrm{~mL}$ of $0.3 \mathrm{M}$ TMAH solution.

The combined TMAH solution was mixed with $45 \mu \mathrm{L}$ of molybdate solution while adjusting the $\mathrm{pH}$ to 1.5 with $6 \mathrm{M} \mathrm{HCl}$. The solution was diluted to $2.5 \mathrm{~mL}$ with water and left to stand for 5-10 min to form heteropoly molybdic acids. A $100-\mu \mathrm{L}$ aliquot of the final solution was injected onto an HPLC column to obtain a sum peak of $\mathrm{P}$ and As at $310 \mathrm{~nm}$. Another $1.0-\mathrm{mL}$ aliquot of the solution was mixed with $20 \mu \mathrm{L}$ of citric acid solution to decompose the molybdoarsenic acid selectively; the mixture was subjected to HPLC for the determination of P. The concentration of As was calculated by subtracting the $\mathrm{P}$ from the sum peak. Calibration graphs were constructed by treating $0.3 \mathrm{M}$ TMAH solutions containing $\mathrm{P}(\mathrm{V})$ and $\mathrm{As}(\mathrm{V})$ at $\mathrm{ng} \mathrm{mL}^{-1}$ levels as described in this paragraph.

\section{Results and Discussion}

\section{Preparation of SPE sorbent}

Admicelles were prepared by mixing PONPE and XAD-4 particles in water. Compared with the previous study, ${ }^{12}$ only a $1 / 10$-amount of XAD-4 was used because the resulting admicelles were employed for trace analytes, not for the iron matrix. The adsorption mechanism of polyoxyethylene-type nonionic surfactants onto polystyrene surfaces has been discussed in the field of surface and colloid chemistry. ${ }^{21-23}$ According to these studies, the surfactant molecules bind their hydrophobic moieties on the polystyrene surfaces by the hydrophobic interaction, thus orientating their hydrophilic ethylene oxide chains toward the aqueous phase. Some organized structures, such as monolayer, hemisphere, and hemicylinder, have been proposed in the literature.

\section{Sorption and desorption of heteropoly molybdic acids}

First, the formation of heteropoly molybdic acids was investigated. At different $\mathrm{pH}$ 's, sample solutions containing $\mathrm{P}(\mathrm{V})$ or $\mathrm{As}(\mathrm{V})$ were mixed with sodium molybdate and analyzed by HPLC. The amount of molybdate should be $<0.35 \mathrm{mg} \mathrm{mL}^{-1}$ (as Mo); otherwise serious fouling of the HPLC column occurred. As shown in Fig. 1, the sufficient complexation was 
Table 1 Separation of $\mathrm{P}(\mathrm{V})$ and $\mathrm{As}(\mathrm{V})$ from $\mathrm{Fe}(\mathrm{III})$ matrix $^{\mathrm{a}}$

\begin{tabular}{clc}
\hline \multirow{2}{*}{ Fe(III) taken/mg } & \multicolumn{2}{c}{ Recovery, \% } \\
\cline { 2 - 3 } & \multicolumn{1}{c}{$\mathrm{P}(\mathrm{V})$} & $\mathrm{As}(\mathrm{V})$ \\
\hline 5.0 & $80,82,86,41^{\mathrm{b}}, 46^{\mathrm{b}}, 51^{\mathrm{b}}$ & $89,90,98$ \\
20 & $81,82,91$ & - \\
40 & $80,84,87,90,91$ & $94,96,97$ \\
60 & $79,80,84$ & - \\
\hline
\end{tabular}

a. Masked with equimolar EDTA.

b. Without EDTA.

achieved around $\mathrm{pH}$ 1.5. The complexation equilibria were attained within $5 \mathrm{~min}$ at room temperature $\left(20-25^{\circ} \mathrm{C}\right)$.

Next, the sorption of heteropoly molybdic acids was investigated. Traces of $\mathrm{P}(\mathrm{V})$ and $\mathrm{As}(\mathrm{V})$ were converted into the heteropoly molybdic acids and introduced onto the SPE column. These heteropoly acids were not found in the column effluent, indicating the complete sorption. This is ascribable to the interaction with the ethylene oxide chains of the PONPEadmicelles, because heteropoly molybdic acids were often extracted into some oxygenic organic solvents, such as ethers and long-chain alcohols. ${ }^{24}$ At the solid-water interfaces, the hydrophilic ethylene oxide chains should protrude toward the aqueous phase and hence can readily interact with the heteropoly acids.

The desorption of heteropoly molybdic acids with acetonitrile was unsatisfactory (e.g., $30-45 \%$ for P); hence an attempt was made to decompose them on the SPE column with an alkaline solution. The recoveries for $\mathrm{P}(\mathrm{V})$ were $65,37,28,62$, and $80 \%$ when working with $0.5 \mathrm{M}$ each of $\mathrm{LiOH}, \mathrm{NaOH}, \mathrm{KOH}, \mathrm{NH}_{3}$, and TMAH solutions, respectively. The recoveries of $78-91 \%$ were also obtained with $0.3 \mathrm{M}$ TMAH solution, though they decreased to $71 \%$ with $0.1 \mathrm{M}$ solution. In the present study, the desorption was performed by adding the eluting agent twice; further additions did not improve the recovery. The incomplete recovery may be due to the irreversible sorption. On the other hand, the recoveries of $95-99 \%$ were obtained for $\mathrm{As}(\mathrm{V})$ with 0.3 M TMAH solution.

\section{Separation of $P(V)$ and $A s(V)$ from $\mathrm{Fe}(I I I)$ matrix}

As described in our previous report, ${ }^{12}$ the sorption of $\mathrm{Fe}(\mathrm{III})$ onto the PONPE-admicelles was quantitative in $6-8 \mathrm{M} \mathrm{HCl}$, while it became negligible in $<2 \mathrm{M} \mathrm{HCl}$. The separation of $\mathrm{P}(\mathrm{V})$ and $\mathrm{As}(\mathrm{V})$ from an $\mathrm{Fe}(\mathrm{III})$ matrix was thus carried out at $\mathrm{pH} 1.5$, which was the optimal $\mathrm{pH}$ for the formation and sorption of the heteropoly acids.

Synthetic sample solutions were prepared by adding $50 \mathrm{ng}$ of $\mathrm{P}(\mathrm{V})$ or $100 \mathrm{ng}$ of $\mathrm{As}(\mathrm{V})$ to acidic $\mathrm{Fe}(\mathrm{III})$ solutions (Fe $5-60$ $\mathrm{mg}$ ). The solutions were treated as described in Analytical procedure. The iron in the final solution was determined by graphite-furnace AAS and found to be $0.6-1 \mu \mathrm{g}$, which corresponds to the removal of $>99.98 \%$. As given in Table 1 , the recovery of $\mathrm{P}(\mathrm{V})$ was maintained at the $80-90 \%$ level by the stoichiometric use of a chelating agent EDTA. The incomplete recovery is ascribable to the loss in the desorption step, as described above. The use of EDTA was indispensable, otherwise the recovery decreased to $41-51 \%$. The possible complexation of $\mathrm{Fe}(\mathrm{III})$ with $\mathrm{P}(\mathrm{V})$ and molybdate ${ }^{25}$ would disturb the formation of the heteropoly acid, leading to the decrease in the recovery. Although the addition of EDTA was essential, its excess addition should be avoided because the excess EDTA made the heteropoly acid decompose (e.g., 9 and $76 \%$ in the presence of 1 and $2 \%$ excess of EDTA, respectively). (a)

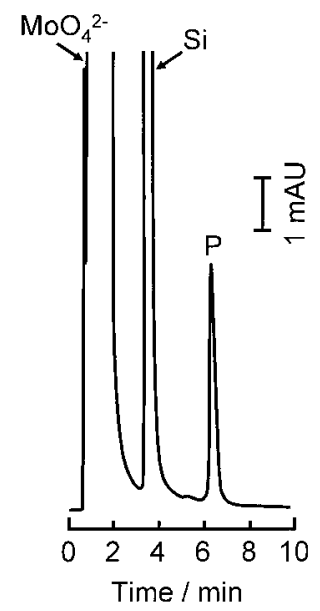

(b)

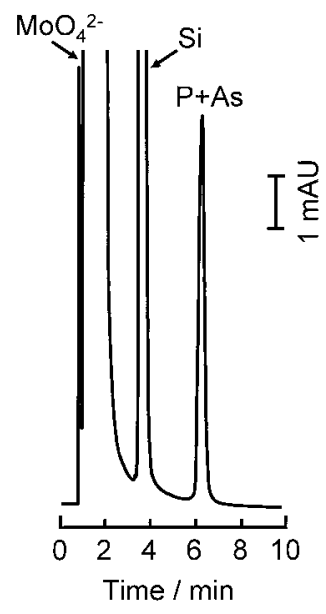

Fig. 2 Typical chromatograms for $5.0 \mathrm{mg}$ of an iron sample, NIST 2168 (P $15 \mu \mathrm{g} \mathrm{g}^{-1}$, As $<1 \mu \mathrm{g} \mathrm{g}^{-1}, \mathrm{Si}<5 \mu \mathrm{g} \mathrm{g}^{-1}$ ). For (b), $75 \mathrm{ng}$ of $\mathrm{As}(\mathrm{V})$ was added to the sample solution before the SPE. HPLC column, Merck Chromolith Performance RP-18e (4.6 mm i.d. $\times 100$ $\mathrm{mm})$; mobile phase, aqueous $65 \%(\mathrm{w} / \mathrm{w})$ acetonitrile containing $0.65 \%(\mathrm{w} / \mathrm{w}) \mathrm{TBABr}$ and $0.10 \%\left(\mathrm{w} / \mathrm{w}\right.$ ) TFA; flow rate, $2.0 \mathrm{~mL} \mathrm{~min}^{-1}$; detection wavelength, $310 \mathrm{~nm}$.

As given in Table 1, As $(\mathrm{V})$ was recovered in $89-97 \%$ yields by the same procedure as that used for $\mathrm{P}(\mathrm{V})$.

\section{Determination of $P(V)$ and $A s(V)$ by $H P L C$}

Because of the insufficient sensitivity of atomic absorption or emission spectrometry, the proposed SPE method was combined with HPLC for the determination of $\mathrm{P}$ and As. Although Tikhomirova et al. reported an ion-pair reversed phase HPLC method for the determination of $\mathrm{Si}(\mathrm{IV})$ and $\mathrm{P}(\mathrm{V})$ in water, ${ }^{26}$ they did not mention the behavior of $\mathrm{As}(\mathrm{V})$.

Figure 2a shows a typical chromatogram for an NIST 2168 sample (certified value: P $15 \mu \mathrm{g} \mathrm{g}^{-1}$, indicative values: As $<1 \mu \mathrm{g}$ $\mathrm{g}^{-1}$ and $\left.\mathrm{Si}<5 \mu \mathrm{g} \mathrm{g}^{-1}\right)$. The analytical signal of $\mathrm{P}(\mathrm{V})$ was completely separated from the large absorbance of the excess molybdate. The peak at 4 min was assignable to molybdosilicic acid, which originated mainly from silicon contaminants on the SPE column; even though polyethylene and Teflon wares were exclusively used in the experiment, the silicon blank was still found to be $0.2-0.5 \mu \mathrm{g}$, which corresponds to $40-100 \mu \mathrm{g} \mathrm{g}^{-1}$ in the NIST sample. On the other hand, As(V) gave the peak at the same position as $\mathrm{P}(\mathrm{V})$, as shown in Fig. 2b. Although the concentrations of acetonitrile and $\mathrm{TBABr}$ were varied, $\mathrm{As}(\mathrm{V})$ behaved similarly to $\mathrm{P}(\mathrm{V})$ in the chromatography.

Therefore, an attempt was made to decompose molybdophosphoric acid or molybdoarsenic acid with an organic acid for the differential determination of $\mathrm{P}(\mathrm{V})$ and $\mathrm{As}(\mathrm{V})$, because some organic acids were often employed as a masking agent in the conventional spectrophotometry with molybdate. ${ }^{24}$ After the formation of heteropoly molybdic acids, sample solutions were mixed with oxalic, citric, or tartaric acid and then injected into the HPLC system. As shown in Fig. 3, these acids provided the complete decomposition of molybdoarsenic acid within $30 \mathrm{~s}$. On the other hand, molybdophosphoric acid was hardly decomposed, especially when working with citric acid; the decomposition rate was 1 and $3 \%$ in the presence of 1.0 and $2.0 \mathrm{mg} \mathrm{mL}^{-1}$ of citric acid, respectively. Therefore, citric acid was employed at $1.0 \mathrm{mg} \mathrm{mL}^{-1}$.

Because the proposed method is based on the SPE and 


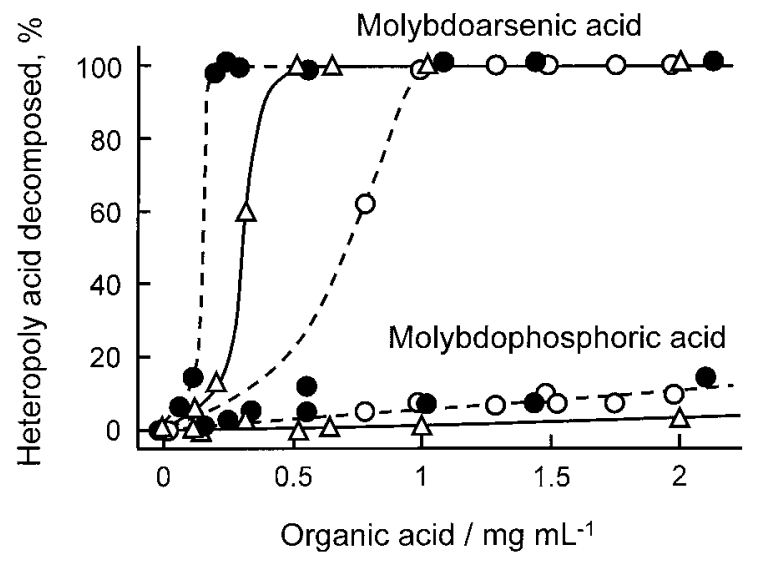

Fig. 3 Decomposition of heteropoly molybdic acids in the presence of oxalic acid $(\bullet)$, citric acid $(\triangle)$, or tartaric acid $(O)$. Concentrations: $\mathrm{P}(\mathrm{V}), 20 \mathrm{ng} \mathrm{mL}^{-1}$; $\mathrm{As}(\mathrm{V}), 100 \mathrm{ng} \mathrm{mL}^{-1}$; $\mathrm{Mo}(\mathrm{VI}), 0.24$ $\mathrm{mg} \mathrm{mL} \mathrm{m}^{-1}$. Decomposition time: $30 \mathrm{~s}$. pH: 1.5 .

Table 2 Analysis of certified reference materials for high-purity iron

\begin{tabular}{|c|c|c|c|}
\hline $\begin{array}{l}\text { Sample } \\
\text { taken/mg }\end{array}$ & $\begin{array}{l}\text { Aliquot } \\
\text { taken }\end{array}$ & Found/ng & $\begin{array}{c}\text { Concentration } \\
\text { in sample } / \mu \mathrm{g} \mathrm{g}^{-1}\end{array}$ \\
\hline \multicolumn{4}{|c|}{ NIST 2168 (chips) } \\
\hline 100 & $1 / 20$ & $\begin{array}{l}\text { P: } 66 \pm 8(n=10) \\
\text { As: ND }{ }^{\mathrm{a}}, \mathrm{ND}, 66^{\mathrm{b}}, 72^{\mathrm{b}}, \\
74^{\mathrm{b}}, 74^{\mathrm{b}}, 77^{\mathrm{b}}\end{array}$ & $\begin{array}{c}13 \pm 2 \\
\mathrm{ND}\end{array}$ \\
\hline \multicolumn{4}{|c|}{ CMSI 1010b (powder) } \\
\hline 503 & $1 / 12.5$ & $\begin{array}{l}\text { P: } 38 \pm 4(n=10) \\
\text { As: } 8,8,9,9,45^{\mathrm{c}}, 51^{\mathrm{c}}\end{array}$ & $\begin{array}{r}0.94 \pm 0.09 \\
0.2 \pm 0.0_{4}\end{array}$ \\
\hline
\end{tabular}

a. Not detected.

b. $75 \mathrm{ng}$ of $\mathrm{As}(\mathrm{V})$ was added.

c. $40 \mathrm{ng}$ of $\mathrm{As}(\mathrm{V})$ was added.

HPLC-spectrophotometry of heteropoly molybdic acids, potential interferences by other molybdate-reactive elements should be considered. Other than the above-mentioned elements, Ge(IV) also formed the heteropoly molybdic acid. It was sorbed on the SPE column and detected at the same retention time as $\mathrm{Si}(\mathrm{IV})$ in the chromatography. However, this element usually exists at negligibly low levels in iron samples.

\section{Analysis of high-purity iron}

Table 2 summarizes the analytical results for two certified reference materials, NIST 2168 and CMSI 1010b. The blanks through the whole procedure were $6 \pm 1 \mathrm{ng}$ for $\mathrm{P}$ and not detected for As $(<3 \mathrm{ng})$. The determined values for $\mathrm{P}$ were almost acceptable but slightly lower than the certified values (15 $\mu \mathrm{g} \mathrm{g}^{-1}$ for NIST 2168 and $1 \mu \mathrm{g} \mathrm{g}^{-1}$ for CMSI 1010b) because of the incomplete desorption as described above. Arsenic was not detected in the NIST material, which was consistent with the indicative value $\left(<1 \mu \mathrm{g} \mathrm{g}^{-1}\right)$. The results for CMSI, however, were considerably lower than the indicative average $\left(1 \mu \mathrm{g} \mathrm{g}^{-1}\right)$, which was derived from the variable data $(<1,<1,<1,1.2$, and $\left.1.3 \mu \mathrm{g} \mathrm{g}^{-1}\right)$. In our experiments, the obtained results were reproducible and the recovery of As was nearly quantitative. At present, the reason for the difference is not clear. The time required for a determination (including SPE and HPLC for P and As) was about 50 min.

In the present study, 100 - to $200-\mu \mathrm{m}$ particles of XAD-4 were used for the preparation of admicelles. Further studies including the use of nano-particles as a solid support would be helpful in improving the SPE efficiency and extending the applicability to other analytical fields, such as biological and environmental analyses.

\section{References}

1. V. Camel, Spectrochim. Acta, Part B, 2003, 58, 1177.

2. R. K. Sharma, S. Mittal, and M. Koel, Crit. Rev. Anal. Chem., 2003, 33, 183.

3. T. P. Rao, R. S. Praveen, and S. Daniel, Crit. Rev. Anal. Chem., 2004, 34, 177.

4. B. Y. Spivakov, G. I. Malofeeva, and O. M. Petrukhin, Anal. Sci., 2006, 22, 503.

5. M. Hiraide, M. H. Sorouradin, and H. Kawaguchi, Anal. Sci., 1994, 10, 125.

6. M. Hiraide, J. Iwasawa, and H. Kawaguchi, Talanta, 1997, 44, 231

7. T. Saitoh, Y. Nakayama, and M. Hiraide, J. Chromatogr., A, 2002, 972, 205.

8. H. Matsumiya, Y. Yatsuya, and M. Hiraide, Anal. Chim. Acta, 2007, 588, 82.

9. R. Atkin, V. S. J. Craig, E. J. Wanless, and S. Biggs, $A d v$. Colloid Interface Sci., 2003, 103, 219.

10. T. Saitoh, N. Hattori, and M. Hiraide, J. Chromatogr., A, 2004, 1028, 149.

11. T. Saitoh, S. Suzuki, and M. Hiraide, J. Chromatogr., A, 2005, 1097, 179.

12. H. Matsumiya, S. Furuzawa, and M. Hiraide, Anal. Chem., 2005, 77, 5344.

13. JIS G 1214, "Methods for Determination of Phosphorus in Iron and Steel", 1992, Japanese Industrial Standards Committee, Tokyo.

14. JIS G 1225, "Methods for Determination of Arsenic in Iron and Steel", 1992, Japanese Industrial Standards Committee, Tokyo.

15. T. Nakahara, Y. Li, H. Takeuchi, and M. Futamura, Tetsu-toHagané, 1999, 85, 97.

16. S. Chanvaivit and I. D. Brindle, J. Anal. At. Spectrom., 2000, 5, 1015.

17. H. Wiltsche, I. B. Brenner, G. Knapp, and K. Prattes, J. Anal. At. Spectrom., 2007, 22, 1083.

18. T. Tanaka, Y. Nakamura, A. Mizuike, and A. Ono, Anal. Sci., 1996, 12, 77.

19. M. Aimoto, H. Kondo, and A. Ono, Tetsu-to-Hagané, 2007, 93, 100.

20. T. Yamane and Y. Tsuchiya, Current Advances in Materials and Processes, 2006, 19, 1280.

21. M. S. Romero-Cano, A. Martín-Rodríguez, and F. J. de las Nieves, J. Colloid Interface Sci., 2000, 227, 322.

22. A. B. Jódar-Reyes, J. L. Ortega-Vinuesa, A. MartínRodríguez, and F. A. M. Leermakers, Langmuir, 2003, 19, 878.

23. A. B. Jódar-Reyes, J. L. Ortega-Vinuesa, and A. MartínRodríguez, J. Colloid Interface Sci., 2005, 282, 439.

24. E. B. Sandell and H. Onishi, "Photometric Determination of Traces of Metals: General Aspects", 1978, John Wiley and Sons, New York, Chichester, Brisbane, Toronto, 249.

25. L. G. Sillén and A. E. Martell, "Stability Constants of Metal-Ion Complexes. Special Publication No. 17’, 1964, The Chemical Society, London.

26. T. I. Tikhomirova, O. V. Krokhin, D. B. Dubovik, A. I. Ivanov, and O. A. Shpigun, J. Anal. Chem., 2002, 57, 18. 